\title{
Conocimientos, actitudes, susceptibilidad y autoeficacia frente a la infección por VIH en adolescentes de Cartagena, Colombia
} \author{
Colombia \\ Irma Yolanda Castillo-Ávila1* orcid.org/0000-0002-4423-0874 \\ Jennifer Paola Ramírez-Aguilar ${ }^{1}$ orcid.org/0000-0001-9336-3182 \\ Karen Patricia Silva-Yepes' ${ }^{1}$ orcid.org/0000-0002-3105-1412 \\ Maira Alejandra Caballero-Pacheco' \\ Karen Arrieta-Yepes ${ }^{1}$ orcid.org/0000-0002-2731-8428
}

Knowledge, attitudes, susceptibility and self-efficacy against HIV infection in adolescents from Cartagena,

1 Facultad de Enfermería, Universidad de Cartagena. Cartagena, Colombia

Castillo-Ávila IY, Ramírez-Aguilar JP, Silva-Yepes KP, Caballero-Pacheco MA, Arrieta-Yepes K. Conocimientos, actitudes, susceptibilidad y autoeficacia frente a la infección por VIH en adolescentes de Cartagena, Colombia. Univ. Salud. 2017;19(1):26-36. DOI: http://dx.doi.org/10.22267/rus.171901.66

\begin{abstract}
Resumen
Objetivo: Determinar los conocimientos, actitudes, susceptibilidad y autoeficacia frente a la infección por VIH en adolescentes escolarizados de la ciudad de Cartagena. Materiales y métodos: Estudio descriptivo transversal, con una población de referencia de 15.686 adolescentes de instituciones educativas oficiales matriculados en los grados $10^{\circ}$ y $11^{\circ}$. Se estimó una muestra de 580 adolescentes, aplicando un muestreo multi-etapico probabilístico. Para la recolección de los datos se utilizó la Escala VIH/SIDA-65, previo consentimiento informado. Los datos fueron procesados en el programa Microsoft Excel y analizados utilizando estadística descriptiva. Resultados: Un total de 579 adolescentes completaron satisfactoriamente el cuestionario, con un promedio de edad de 15,6 años (DE $=0,9$ años), mayoritariamente de sexo femenino (65,6\% (380)). El 45\% (261) presenta conocimientos deficientes, 55\% (318) ideas erróneas sobre la enfermedad, 69,6\% (400) mostraron actitudes negativas, 46,1\% (266) no se consideran susceptibles para contraer la enfermedad y 49,5\% (286) mostró baja autoeficacia para la prevención de la infección. Conclusión: Los pocos conocimientos sobre el VIH y sus modos de transmisión, mezclados con ideas erróneas aumentan la probabilidad de contraer la infección entre los adolescentes, sobre todo, cuando se suman actitudes negativas, baja percepción de susceptibilidad y poca autoeficacia para la prevención.
\end{abstract}

Palabras clave: Adolescente; conocimientos, actitudes y prácticas en salud; VIH; salud sexual; autoeficacia. (Fuente: DeCS, Bireme).

\begin{abstract}
Objective: To determine knowledge, attitudes, susceptibility and self-efficacy facing HIV infection in school adolescents in the city of Cartagena. Materials and methods: A descriptive cross-sectional study was made with a reference population of 15,686 adolescents from formal educational institutions who are enrolled in tenth and eleventh grades. A sample of 580 adolescents was estimated, and a probabilistic multi-stage sample was applied. The HIV/AIDS-65 Scale was used for data collection, previous informed consent. The data were processed using the
\end{abstract}


Microsoft Excel program and were analyzed using descriptive statistics. Results: A total of 579 adolescents with an average age of 15.6 years $(=0.9$ years), mainly of female sex $(65.6 \%$ (380)) successfully completed the questionnaire. The $45 \%$ (261) presents deficient knowledge, 55\% (318) presents misconceptions about the disease, $69.6 \%$ (400) showed negative attitudes, $46.1 \%$ (266) do not considered themselves susceptible to contract the disease and 49.5\% (286) showed low self-efficacy for the prevention of the infection. Conclusion: Little knowledge about HIV and its modes of transmission, mixed with misconceptions, increases the likelihood of infection among adolescents, especially when negative attitudes, low perception of susceptibility and little self-efficacy for prevention are combined.

Keywords: Adolescent; health knowledge, attitudes, practice; HIV; sexual health; self-efficacy. (Source: DeCS, Bireme).

\section{Introducción}

La infección por el Virus de Inmunodeficiencia Humana (VIH) es una de las enfermedades pandémicas que más ha marcado el desarrollo de las diferentes poblaciones en el mundo. Según el comportamiento estadístico de esta patología, entre los grupos de edad con mayor vulnerabilidad se encuentran los adolescentes y jóvenes de 15 a 24 años y se mantiene una tendencia sostenida de la infección en los países de América Latina ${ }^{1}$.

A nivel mundial el panorama epidemiológico de este evento, de interés en salud pública, muestra que el número de adolescentes dentro de la población afectada es cada vez mayor. La deficiencia en los conocimientos se percibe como una de las mayores razones por las que aumenta la vulnerabilidad en esta población, sobre la cual influyen creencias y mitos de origen cultural. Además, la transmisión entre pares de ideas erróneas aumenta prácticas inadecuadas $\mathrm{y}$ aumenta la exposición a la enfermedad, generando un mayor impacto social ${ }^{2}$. Como adolescentes los jóvenes se enfrentan a una etapa del ciclo vital individual donde se presentan diferentes cambios físicos, psicológicos y sociales, que se conjugan con el entorno y se ven con gran fuerza influidos por el conocimiento de otros jóvenes, que también tienen limitados conocimientos sobre el tema y pobres prácticas para el cuidado de la salud ${ }^{1-3}$.

Los jóvenes a lo largo de esta etapa de la vida se enfrentan a factores de riesgo, entre ellos tener relaciones sexuales sin ningún tipo de protección y tener déficit de conocimientos con relación al Virus de Inmunodeficiencia Humana/Síndrome de Inmunodeficiencia Adquirida (VIH/Sida), es por esto que alrededor de la mitad de los nuevos casos de esta infección está representada por jóvenes. La familia, los estilos de vida saludables, los conocimientos, el asesoramiento y las pruebas voluntarias, son factores que se relacionan con la disminución de los factores de riesgo, convirtiéndose así en estrategias indispensables para la gestión y prevención de la infección por VIH. A pesar de las numerosas estrategias para intentar la modificación de las conductas de riesgo, cada vez es mayor el número de personas contagiadas a nivel mundial ${ }^{4-9}$.

En el departamento de Bolívar la tasa de mortalidad asociada a esta enfermedad, muestra una tendencia al aumento, reportándose 37,6 casos de VIH/Sida y muerte por cada $100 \mathrm{mil}$ habitantes ${ }^{10}$. Cartagena la ciudad capital, se ubica como una de las 7 ciudades principales del país, donde la prevalencia de la enfermedad es superior al 5\%, en la población de jóvenes entre los 18 y 24 años, que corresponde al $10 \%$ del total de casos en este grupo etario ${ }^{10,11}$. Lo anterior resalta la importancia del fortalecer estrategias de orientación y educación para la prevención de la infección por VIH entre los jóvenes de las zonas más vulnerables de la ciudad, por la amplia exposición a riesgos relacionados con la enfermedad, como el consumo de sustancias psicoactivas y el comercio sexual en el contexto turístico de la ciudad11,12.

Múltiples factores influyen en la adopción de conductas de riesgo, es fundamental su conocimiento para así intervenirlos y alcanzar una mejor calidad de vida en la población. Identificar los conocimientos, las actitudes, la 
susceptibilidad y la autoeficacia de la población adolescente, es una herramienta valiosa para la construcción de estrategias que impacten y contribuyan con la disminución de conductas de riesgo, estos elementos se constituyen como factores protectores frente a la enfermedad, aportando significativamente al aumento de las conductas saludables y la vida sexual de calidad en esta población ${ }^{12}$.

El Programa Conjunto de las Naciones Unidas sobre el VIH/sida (ONUSIDA), refiere que la percepción de riesgo es la susceptibilidad de un individuo a las consecuencias negativas de una conducta determinada; y con relación al VIH, el riesgo es considerado como la probabilidad que tiene cualquier ser humano de adquirir el VIH; al evaluar la percepción de riesgo frente a la infección por VIH en los adolescentes, se han encontrado diferentes estudios donde se plantea que es muy baja ${ }^{2,13-16}$, principalmente porque los adolescentes no cuentan con suficiente información sobre el tema, muestran pobres conocimientos sobre la enfermedad y su modo de trasmisión y escasas habilidades para la prevención ${ }^{16}$.

La deficiencia en los conocimientos y las prácticas sexuales inseguras potencian el riesgo de la enfermedad entre los jóvenes. El inicio de la actividad sexual a edades más tempranas y el consecuente aumento del número de parejas sexuales, aumenta la exposición a la enfermedad y el índice de nuevos casos entre esta población. Por tanto, una educación en salud sexual adecuada retrasa el inicio de las relaciones sexuales y se asocia con un mayor y mejor uso de anticonceptivos ${ }^{17,18}$.

Las actitudes también influyen en las conductas de riesgo, por tanto la percepción social y la actitud frente al VIH determinan el comportamiento frente a la infección ${ }^{13}$. Algunos mitos presentes entre los jóvenes, las posturas de la sociedad o las creencias transmitidas en el entorno cercano pueden influir en las actitudes que el adolescente asume hacia su propia sexualidad y frente a las percepciones que tienen de aquellas personas que viven con la infección ${ }^{9}$.
La percepción de susceptibilidad y la autoeficacia son variables que ayudan a encaminar a los jóvenes hacia conductas positivas para prevenir la infección. Diversos investigadores han encontrado que la mayoría de los adolescentes presentan déficit en el nivel de auto-eficacia y una pobre percepción de susceptibilidad frente a la enfermedad; que sumado a las características propias de su edad, desencadenan la ejecución de comportamientos de riesgo para la infección ${ }^{9}$. Los estilos de vida de los jóvenes envuelven comportamientos más riesgosos que entre la población de mayor edad. La mayoría de ellos alcanzan la madurez sexual mucho antes de alcanzar la madurez emocional, cognitiva o social, lo que se asocia frecuentemente con inicio temprano de relaciones sexuales, promiscuidad y no uso de anticonceptivos, lo cual incide en la alta tasa de enfermedades de transmisión sexual en este grupo ${ }^{3,19}$.

Teniendo en cuenta dicho panorama, la Organización de las Naciones Unidas para la Educación, la Ciencia y la Cultura (UNESCO) proyecta que para el año 2030 más de 40 millones de adolescentes de todo el mundo se infectará del virus, dato que resalta la importancia de intervenir en la prevención de la trasmisión de la enfermedad ${ }^{9}$. Por todo lo anterior esta investigación se propuso determinar los conocimientos, actitudes, susceptibilidad y autoeficacia frente a la infección por VIH en adolescentes escolarizados de la ciudad de Cartagena.

\section{Materiales y métodos}

Se realizó un estudio descriptivo transversal, con una población de referencia de 15.686 adolescentes matriculados en los grados 10 y 11 de las instituciones educativas oficiales de la zona urbana de Cartagena. Se estimó un tamaño de muestra de 567 adolescentes, calculada teniendo en cuenta un nivel de confianza de 95\% y un marguen de error del 3\% seleccionados mediante muestreo probabilístico estratificado con afijación proporcional teniendo en cuenta el número de adolescentes matriculados en cada 
grado y en cada colegio o institución educativa incluida. Para la recolección de la información se utilizó la Escala VIH/SIDA-65, desarrollada por Paniagua et al. ${ }^{7}$ y utilizada en varias investigaciones ${ }^{16,19}$ que consta de 65 ítems y se compone de cinco sub-escalas: 1 . Conocimientos sobre hechos relacionados con el VIH/sida, (20 ítems); 2.Ideas erróneas acerca de la enfermedad (20 ítems); 3. Actitudes negativas frente a la infección por $\mathrm{VIH} /$ sida o frente a quienes conviven con ella (15 ítems); 4. Susceptibilidad frente al VIH/sida (5 ítems) y Autoeficacia en la prevención de la infección por el VIH (5 ítems). Para las sub-escalas que evalúan conocimientos e ideas erróneas las opciones de respuesta son: "Falso", "Verdadero" y "No sé", para las otras subescalas las opciones de respuesta a todos los ítems son: "De acuerdo", "En desacuerdo" y "No sé". Los datos fueron procesados en el programa Microsoft Excel y analizados utilizando estadística descriptiva.

En esta investigación consideró todas las subcategorías estudiadas en el instrumento, asignado un valor porcentual a las puntuaciones para la calificación y clasificación general de los resultados, de acuerdo a lo propuesto por los autores. Por tanto para la calificación de los conocimientos, se considera un buen nivel, si se responde de manera acertada del $80-100 \%$ de las preguntas, regular si el puntaje se encontraba entre $60-80 \%$ y malo si el porcentaje es menor de $60 \%$. Para la escala de actitudes, se consideraron positivas o favorables aquellas con un porcentaje superior al $60 \%$ y negativas las de porcentaje inferior. Esta misma escala porcentual, se aplica para la determinación de la susceptibilidad y la autoeficacia (esta última calificada como baja y alta). La selección de los participantes se realizó utilizando un muestreo probabilístico y el auto-diligenciamiento de las encuestas ayudo a controlar los sesgos de selección e información. Fue realizada una prueba piloto para identificar aspectos del cuestionario que pudieran causar confusión a los estudiantes participantes.

\section{Consideraciones éticas}

La investigación respetó los parámetros éticos para estudios con seres humanos contenidos en la Resolución 008430 de 1993 del Ministerio de Salud de Colombia, la declaración de Helsinki y el código de ética de enfermería. Los estudiantes participantes firmaron un consentimiento informado, previa explicación de los objetivos del estudio, los menores de edad firmaron el asentimiento y se obtuvo además la autorización por escrito del tutor legal.

\section{Resultados}

\section{Características socio-demográficas de los estudiantes participantes del estudio}

En el estudio participaron 579 estudiantes de grado $10^{\circ}$ y $11^{\circ}$ de instituciones educativas oficiales de Cartagena con edades comprendidas entre 15 y 19 años, y edad promedio de 15.9 años (DE $=0,9$ años). El $64.7 \%$ (375) son mujeres, $43.3 \%$ (251) están clasificados en el estrato socioeconómico 1 y solo el $4.4 \%$ (26) viven en unión libre (Tabla 1).

Tabla 1. Distribución de variables socio demográficas de los adolescentes escolarizados de la ciudad de Cartagena. 2015

\begin{tabular}{lrr}
\hline \multicolumn{1}{c}{ Característica } & Frecuencia & Porcentaje \\
\hline Sexo & & \\
Femenino & 375 & 64.7 \\
Masculino & 204 & 35.3 \\
Estrato & & \\
socioeconómico & & \\
1 & 251 & 43.3 \\
2 & 231 & 39.8 \\
3 & 88 & 15.1 \\
4 & 12 & 2.07 \\
5 & 1 & 0.17 \\
6 & 1 & 0.17 \\
Estado civil & & \\
Soltero & 553 & 95.6 \\
Unión libre & 26 & 4.4 \\
Total & $\mathbf{5 7 9}$ & $\mathbf{1 0 0}$ \\
\hline Fuente: Resultados del estudio & &
\end{tabular}

\section{Conocimientos sobre la infección por VIH de los adolescentes participantes}

Con relación a los conocimientos que tienen los estudiantes sobre la infección por VIH se encontró que $82.4 \%$ (477) de los estudiantes piensa que se puede transmitir de forma vertical, 90.8\% (526) afirma que se puede transmitir a 
través del semen, $94 \%$ (544) piensa que los hombres pueden infectar a las mujeres, menor proporción (91\% (527)) están de acuerdo que la mujer puede infectar al hombre. El 22,5\% (130) no sabe que el virus debilita la capacidad del cuerpo para combatir las infecciones y solo el $58.4 \%$ (338) piensa que se puede contraer a través de penetración anal (Tabla 2).

Tabla 2. Conocimientos frente a la infección por VIH en adolescentes escolarizados de Cartagena

\begin{tabular}{|c|c|c|c|c|c|c|c|}
\hline Conocimientos & $\mathbf{F}$ & $\%$ & $\mathbf{V}$ & $\%$ & No sé & $\%$ & Total \\
\hline $\begin{array}{l}\text { Una mujer embarazada que tenga el virus del sida } \\
\text { puede transmitírselo a su feto }\end{array}$ & 27 & 4,7 & 477 & 82,4 & 75 & 13,0 & 579 \\
\hline $\begin{array}{l}\text { Se puede transmitir el virus del sida a través del } \\
\text { semen }\end{array}$ & 8 & 1,4 & 526 & 90,8 & 45 & 7,8 & 579 \\
\hline $\begin{array}{l}\text { Usar un condón durante la relación sexual puede } \\
\text { reducir el riesgo de contraer el virus del sida }\end{array}$ & 50 & 8,6 & 481 & 83,1 & 48 & 8,3 & 579 \\
\hline $\begin{array}{l}\text { Se puede contraer el virus del sida a través de las } \\
\text { relaciones sexuales con penetración entre un hombre } \\
\text { y una mujer }\end{array}$ & 9 & 1,6 & 537 & 92,7 & 33 & 5,7 & 579 \\
\hline $\begin{array}{l}\text { Los hombres con el virus del sida pueden infectar a las } \\
\text { mujeres }\end{array}$ & 14 & 2,4 & 544 & 94,0 & 21 & 3,6 & 579 \\
\hline $\begin{array}{l}\text { El sida es una enfermedad que puede causar la muerte } \\
\text { de la persona }\end{array}$ & 14 & 2,4 & 540 & 93,3 & 25 & 4,3 & 579 \\
\hline $\begin{array}{l}\text { Recibir una transfusión o donación de sangre infectada } \\
\text { con el virus del sida puede transmitirle a una persona } \\
\text { el virus del sida }\end{array}$ & 9 & 1,6 & 533 & 92,1 & 37 & 6,4 & 579 \\
\hline $\begin{array}{l}\text { Las mujeres infectada con el virus sida pueden } \\
\text { infectar a los hombres }\end{array}$ & 14 & 2,4 & 527 & 91,0 & 38 & 6,6 & 579 \\
\hline $\begin{array}{l}\text { Las personas con el virus del sida pueden contraer } \\
\text { otras enfermedades debido al sida }\end{array}$ & 37 & 6,4 & 314 & 54,2 & 228 & 39,4 & 579 \\
\hline En la actualidad, no hay cura conocida para el sida & 118 & 20,4 & 322 & 55,6 & 139 & 24,0 & 579 \\
\hline $\begin{array}{l}\text { Una persona puede ser infectada con el virus del sida y } \\
\text { no presentar ningún síntoma de enfermedad }\end{array}$ & 142 & 24,5 & 244 & 42,1 & 193 & 33,3 & 579 \\
\hline $\begin{array}{l}\text { Las personas pueden tener el virus del sida en su } \\
\text { cuerpo y no estar enfermas }\end{array}$ & 136 & 23,5 & 245 & 42,3 & 198 & 34,2 & 579 \\
\hline $\begin{array}{l}\text { El virus del sida debilita la capacidad del cuerpo para } \\
\text { combatir las infecciones }\end{array}$ & 36 & 6,2 & 413 & 71,3 & 130 & 22,5 & 579 \\
\hline $\begin{array}{l}\text { Se puede contraer el virus del sida a través de } \\
\text { penetración anal }\end{array}$ & 59 & 10,2 & 338 & 58,4 & 182 & 31,4 & 579 \\
\hline $\begin{array}{l}\text { El virus del sida puede transmitirse entre dos varones } \\
\text { que tengan relaciones sexuales }\end{array}$ & 83 & 14,3 & 322 & 55,6 & 174 & 30,1 & 579 \\
\hline $\begin{array}{l}\text { Se puede contraer el sida a través de alguien que esté } \\
\text { infectado aunque no manifiesta ningún síntoma de la } \\
\text { enfermedad }\end{array}$ & 52 & 9,0 & 394 & 68,0 & 133 & 23,0 & 579 \\
\hline
\end{tabular}


En cuanto a las ideas erróneas frente a la infección por VIH, se encontró que 22,5\% (130) piensa que se puede contraer compartiendo cuchillos, tenedores o vasos; el $32.1 \%$ (186) piensa que se puede contraer a través de la saliva y $38.5 \%$ (223) cree que se puede contraer el virus en una piscina. Otras ideas erróneas se muestran en la Tabla 3.

Tabla 3. Ideas erróneas frente a la infección por VIH en adolescentes escolarizados de Cartagena

\begin{tabular}{|c|c|c|c|c|c|c|c|}
\hline Afirmaciones e ideas erróneas & $\mathbf{F}$ & $\%$ & $\mathbf{V}$ & $\%$ & $\begin{array}{l}\text { No } \\
\text { sé }\end{array}$ & $\%$ & Total \\
\hline Se puede contraer el virus del sida compartiendo cuchillos, tenedores o vasos & 347 & 59,9 & 130 & 22,5 & 102 & 17,6 & 579 \\
\hline $\begin{array}{l}\text { Todas las mujeres que tienen relaciones sexuales con otras mujeres tienen el } \\
\text { virus del sida }\end{array}$ & 344 & 59,4 & 33 & 5,7 & 202 & 34,9 & 579 \\
\hline $\begin{array}{l}\text { Uno puede contraer el virus del sida tocando o estando cerca de una persona } \\
\text { con el virus }\end{array}$ & 489 & 84,5 & 45 & 7,8 & 45 & 7,8 & 579 \\
\hline $\begin{array}{l}\text { Es posible que una persona contraiga el virus del sida hablando a través de un } \\
\text { teléfono público }\end{array}$ & 529 & 91,4 & 11 & 1,9 & 39 & 6,7 & 579 \\
\hline Se puede contraer el virus del sida compartiendo la ropa con otra persona & 356 & 61,5 & 72 & 12,4 & 151 & 26,1 & 579 \\
\hline $\begin{array}{l}\text { Se puede contraer el virus del sida usando objetos personales de otra persona } \\
\text { como una peinilla o un cepillo del cabello }\end{array}$ & 399 & 68,9 & 63 & 10,9 & 117 & 20,2 & 579 \\
\hline El estornudar y el toser pueden trasmitir el virus del sida & 277 & 47,8 & 107 & 18,5 & 195 & 33,7 & 579 \\
\hline Se puede contraer el virus del sida en una piscina & 284 & 49,1 & 72 & 12,4 & 223 & 38,5 & 579 \\
\hline
\end{tabular}

\section{Actitud sobre la infección por VIH de los adolescentes participantes}

Con respecto a las actitudes de los adolescentes frente a la infección por VIH, un 23,1\% (134) no saben si rechazarían sentarse cerca de una persona con infección por VIH y un 7,3\% (42) estaría de acuerdo en hacerlo, el 49,7\% (288) se sentiría incomodo/a usando el mismo servicio y vestuario que estas personas, el $12,4 \%$ (72) no sabe si estaría de acuerdo o no en permitir que una persona con infección por VIH utilice un autobús público, el 12,6\% (73) no sabe si debería permitirse que estas personas vivan en edificios de apartamentos, el 20,2\% (117) (Tabla 4).

Tabla 4. Actitudes frente a la infección por VIH en adolescentes escolarizados de Cartagena

\begin{tabular}{|c|c|c|c|c|c|c|c|}
\hline Actitudes negativas & De acuerdo & $\%$ & En desacuerdo & $\%$ & No sé & $\%$ & Total \\
\hline $\begin{array}{l}\text { Rechazaría sentarme cerca de una } \\
\text { persona que tiene el virus del sida }\end{array}$ & 42 & 7,3 & 403 & 69,6 & 134 & 23,1 & 579 \\
\hline $\begin{array}{l}\text { Me sentiría incómodo/a usando el } \\
\text { mismo servicio y vestuario que } \\
\text { personas con el virus del sida }\end{array}$ & 288 & 49,7 & 176 & 30,4 & 115 & 19,9 & 579 \\
\hline
\end{tabular}




$\begin{aligned} & \text { Las personas que tienen el vih } \\ & \text { deberían ser apartadas para } \\ & \text { garantizar la seguridad de los } \\ & \text { demás }\end{aligned}$
$\begin{aligned} & \text { No se debería permitir que las } \\ & \text { personas con el sida utilicen los }\end{aligned}$
$\begin{aligned} & \text { autobuses públicos } \\ & \text { No se debería permitir que las }\end{aligned}$

\section{Susceptibilidad sobre la infección por VIH de los adolescentes participantes}

En cuanto a la variable susceptibilidad ante afirmaciones que fueron puestas a consideración de los jóvenes al consultárseles si ellos directamente se creían la clase de persona que pudiera contraer el virus del sida 53.9\% (312) respondió estar en desacuerdo; y si la pregunta se dirigía a que sólo los homosexuales varones deberían preocuparse del sida el 67\% (388) respondió estar en desacuerdo (Tabla 5). En general el $46.1 \%$ (266) no se consideran susceptibles de padecer la infección y el 58.4\% (313) tienen un buen nivel de susceptibilidad.

Tabla 5. Susceptibilidad frente a la infección por VIH en adolescentes escolarizados de Cartagena

\begin{tabular}{|c|c|c|c|c|c|c|c|}
\hline Susceptibilidad & $\begin{array}{c}\text { De } \\
\text { Acuerdo }\end{array}$ & $\%$ & $\begin{array}{c}\text { En } \\
\text { Desacuerdo }\end{array}$ & $\%$ & $\begin{array}{l}\text { No } \\
\text { sé }\end{array}$ & $\%$ & Total \\
\hline $\begin{array}{l}\text { Creo que sólo las personas que se inyectan drogas } \\
\text { tienen que preocuparse por el sida }\end{array}$ & 41 & 7,1 & 400 & 69,1 & 138 & 23,8 & 579 \\
\hline $\begin{array}{l}\text { EL sida es un problema de salud que suele darse en } \\
\text { otros países por lo tanto, no es algo de lo que la gente } \\
\text { de mi país tenga que preocuparse }\end{array}$ & 46 & 7,9 & 479 & 82,7 & 54 & 9,3 & 579 \\
\hline $\begin{array}{l}\text { Yo no soy la clase de persona que pueda contraer el } \\
\text { virus del sida }\end{array}$ & 111 & 19,2 & 312 & 53,9 & 156 & 26,9 & 579 \\
\hline $\begin{array}{l}\text { Yo no me tengo que preocupar sobre la posibilidad de } \\
\text { contraer el virus del sida }\end{array}$ & 76 & 13,1 & 442 & 76,3 & 61 & 10,5 & 579 \\
\hline $\begin{array}{l}\text { Creo que sólo los homosexuales varones deberían } \\
\text { preocuparse del sida }\end{array}$ & 84 & 14,5 & 388 & 67,0 & 107 & 18,5 & 579 \\
\hline
\end{tabular}

\section{Autoeficacia sobre la infección por VIH de los adolescentes participantes}

En autoeficacia los resultados muestran que el 93.1\% (539) de los adolescentes se considera capaz de pedirle a su pareja que use condón; en contraste el 49.5\% (287) de los participantes manifestaron no poder o no saber si eran capaces de conseguir condones fácilmente, y solo el 51.1\% (296) es capaz de contarle a su pareja si han tenido relaciones sexuales con alguien bisexual. (Tabla 6). En general el 49.5\% (286) de los adolescentes encuestados tienen baja autoeficacia y el $50.4 \%$ (293) un alto nivel de autoeficacia. 
Tabla 6. Autoeficacia frente al uso del condón para la prevención de VIH en adolescentes escolarizados de Cartagena

\begin{tabular}{|c|c|c|c|c|c|c|c|}
\hline Afirmaciones autoeficacia & $\begin{array}{c}\text { De } \\
\text { acuerdo }\end{array}$ & $\%$ & $\begin{array}{c}\text { En } \\
\text { desacuerdo }\end{array}$ & $\%$ & No sé & $\%$ & Total \\
\hline $\begin{array}{l}\text { Soy capaz de pedirle a mi pareja } \\
\text { sexual que usemos un condón }\end{array}$ & 539 & 93,1 & 14 & 2,4 & 26 & 4,5 & 579 \\
\hline $\begin{array}{l}\text { Soy capaz de comprar o conseguir } \\
\text { condones fácilmente }\end{array}$ & 292 & 50,4 & 145 & 25,0 & 142 & 24,5 & 579 \\
\hline $\begin{array}{l}\text { Soy capaz de preguntarle a mi } \\
\text { pareja si ha mantenido relaciones } \\
\text { sexuales con alguien que se } \\
\text { prostituya }\end{array}$ & 432 & 74,6 & 67 & 11,6 & 80 & 13,8 & 579 \\
\hline $\begin{array}{l}\text { Soy capaz de contarle a mi pareja } \\
\text { si he tenido relaciones sexuales } \\
\text { con una persona bisexual }\end{array}$ & 296 & 51,1 & 140 & 24,2 & 143 & 24,7 & 579 \\
\hline $\begin{array}{l}\text { Soy capaz de llevar condón por si } \\
\text { decido } \\
\text { sexuales }\end{array}$ & 402 & 69,4 & 74 & 12,8 & 103 & 17,8 & 579 \\
\hline
\end{tabular}

\section{Discusión}

En esta investigación se observó que los adolescentes tienen un nivel de conocimientos regular o deficiente sobre la enfermedad que sumado a las características propias de la edad puede llegar a producir conductas de riesgo, en especial por el desconocimiento sobre los modos de transmisión, prevención y evolución de la enfermedad; lo que a su vez se deriva en ideas erróneas y actitudes y prácticas negativas, que potencian el riesgo de infección.

El nivel de conocimiento sobre la enfermedad no garantiza el comportamiento preventivo de los adolescentes, pero puede ser un coadyuvante para mejorarlo y disminuir el grado de ideas erróneas que ellos presenten; hallazgo que coincide con la investigación realizada por Uribe en un estudio realizado con 222 adolescentes en la ciudad de Cali, donde plantea que los conocimientos no están directamente relacionados con las conductas de prevención si no que solo disminuyen la probabilidad de transmisión y la presencia de ideas erróneas ${ }^{7}$.
Según Cobos et al., en un estudio realizado en Nicaragua, a partir de varios grupos de discusión, se ha demostrado que los conocimientos son un factor de protección frente al VIH, pero que tener ese conocimiento no garantiza practicas adecuadas a largo plazo; además establece que la familia, la escuela y los grupos de iguales, juegan un papel fundamental en la trasmisión de elementos culturales relacionados con la educación sexual ${ }^{8}$. Del mismo modo Sisay et al., establecen que a pesar de saber sobre el VIH algunos adolescentes tienen conductas de riesgo, así mismo perciben como bajo el riesgo de adquirir la infección; lo que los lleva a recomendar la orientación sexual en el tema de VIH como parte del plan de estudios de todas las instituciones 9 .

El riego de adquirir VIH además de estar ligado a la etapa del individuo también se deriva de los vacíos en conocimiento de los adolescentes como lo mostró esta investigación, lo que puede deberse a la calidad y a la fuente de este conocimiento; teniendo en cuenta lo que plantea Díaz, en un estudio realizado con 919 estudiantes en la ciudad de Cartagena de indias, quien manifiesta que el déficit de conocimientos 
puede ser debido a que la información sobre sexualidad que reciben los jóvenes suele ser superficial, desvirtuada y fragmentada, siendo rutinaria o con muchos estereotipos y la mayoría de las veces no ofrece información sobre situaciones o preocupaciones individuales ${ }^{10}$.

Así mismo, Gómez y Cogollo en su investigación realizada con 2625 estudiantes de secundaria de Cartagena sugieren fortalecer la educación en salud sexual y reproductiva con una visión integral que permita la adopción de conocimientos y valores personales y pro sociales que se expresen a diario en comportamientos saludables, de autocuidado, de respeto de la propia integridad física y de la pareja ${ }^{12}$. Por tanto, es importante resaltar, que en la formación y modificación de actitudes y conductas de los jóvenes, el contexto social y la comunicación asertiva (con padres, maestros, profesionales de salud) juegan un papel fundamental.

Por otro lado los conocimientos influyen en las actitudes y posturas que los adolescentes asumen frente a las personas infectadas por $\mathrm{VIH} /$ sida en la presente investigación se evidencia que los adolescentes tienen conocimientos regulares y deficientes y esto se ve reflejado en las actitudes negativas que se tienen frente a las personas infectadas por VIH. Aun cuando muchos manifiestan tolerarlas y estar de acuerdo con que no deberían ser discriminadas por su condición de enfermedad; al consultarles directamente sobre si estarían dispuestos a compartir espacios privados con ellas como vestuarios o ser atendidos por ellas, su opinión cambia. Bermúdez et al., en un estudio realizado con 10.130 adolescentes de entre 13 y 18 años, encontró que es alto el nivel de conocimientos sobre el VIH en la población, sin embargo existen ideas erróneas, que los llevan a adoptar actitudes negativas y comportamientos de riesgo, las ideas falsas que se han mantenido a través del tiempo justifican, para muchos jóvenes, la estigmatización que siempre ha existido frente a la infección por el $\mathrm{VIH}^{5,13}$.

Las diferentes posturas halladas en la sociedad frente a la infección o las creencias transmitidas sobre esta, influyen en las actitudes que los adolescentes asumen bien sea frente a su sexualidad o a las personas diagnosticadas con la enfermedad. Debido a las características propias del ciclo vital, los adolescentes buscan un lugar en la sociedad $y$ pueden ser fácilmente influenciados por el medio en el que se desenvuelven; por esto, muchos pueden estar de acuerdo con afirmaciones como que las personas portadoras de virus del sida merezcan estar infectados ${ }^{10,12,14}$.

Es importante resaltar que el simple hecho de ser adolescente genera vulnerabilidad, en esta investigación se hizo énfasis en ello para sopesar hasta qué grado los adolescentes realmente se perciben susceptibles ante la enfermedad. De cara a los resultados obtenidos con respecto a esta variable, se puede decir que los adolescentes tienen un bajo nivel de susceptibilidad o no se consideran susceptibles ante este virus; aun cuando conocen que el VIH es un problema de cuidado en Colombia y se muestran preocupados por la posibilidad de infectarse con el virus, consideran que este hecho está muy lejos ellos, o bien consideran que no son el tipo de personas que podrían adquirir esta enfermedad ${ }^{14,16}$.

La creencia de ser susceptible ante el VIH debería repercutir en una conducta protectora que se conoce como autoeficacia. Este característica influye en los diversos comportamientos del ser humano y es la que finalmente puede llevar a los adolescentes a conservar o no hábitos encaminados a mantener el estado de salud, prevenir la enfermedad y mitigar los riesgos. Esto responde al planteamiento de Bandura, quien afirma que la conducta esta mediada por un proceso de evaluación cognitiva, en la cual se integran conocimientos, expectativas de resultados, estados emocionales, influencias sociales $y$ experiencias pasadas, de forma que se crea una estimación de la habilidad, capacidad o autoeficacia, para afrontar una determinada situación ${ }^{14,15 .}$

Por su parte Uribe et al., plantean que se hace estrictamente necesario que las intervenciones encaminadas al cambio de conductas, actitudes y 
comportamientos en adolescentes, tengan en cuenta características como la edad, el género, el nivel de escolaridad y el nivel socioeconómico. ${ }^{16}$ De esta forma seria más probable la garantía de entendimiento e interiorización de la información para su posterior puesta en práctica. La muestra de adolescentes de la presente investigación proyectaron un "buen nivel de autoeficacia" en la medida que se consideran capaces de hablar con su pareja sexual de gran variedad de temáticas relacionadas con su pasado sexual, así como sus preferencias sexuales y lo que desean para su relación actual; sin embargo, pese a esto un porcentaje significativo de adolescentes expresan limitaciones para adquirir preservativos, lo que pueden entorpecer la posibilidad de instaurar una conducta protectora mediada por la autoeficacia, y esto en realidad supondría poca autoeficacia para la prevención de la infección ${ }^{15}$.

Esta investigación permitió una mayor compresión de las herramientas que disponen los adolescentes para prevenir la infección por VIH, además se aproxima a la evaluación de los programas de salud sexual dirigidos a los adolescentes, tanto de los servicios de salud, como educativos y a la calidad de la información que estos adolescentes en riesgo reciben en el contexto escolar; toda vez, que son vulnerables no solo por las dinámicas sociales y familiares en las que se desarrollan, sino también por la naturaleza de la etapa en la que se encuentra. La principal fortaleza de este estudio, además de la información que deriva, fue el hecho que los adolescentes participantes se instruyeron en el tema de VIH/sida y fueron resueltas las dudas que estos presentaron por medio de charlas educativas, dando de esta manera un aporte valioso para la construcción de conocimientos adecuados que ayuden a estos adolescentes a mejorar su percepción frente a esta enfermedad y a reducir las prácticas de riesgo.

La poca disposición de algunas instituciones para la realización de las encuestas a los adolescentes, por las múltiples actividades académicas programadas en estos cursos y las demoras en la consecución del consentimiento informado por parte de los padres se configuran como las principales limitaciones de la investigación.

\section{Conclusiones}

A pesar de que los jóvenes escolarizados de las instituciones oficiales de la ciudad de Cartagena, son instruidos en temas de salud sexual y reproductiva tienen pocos conocimientos sobre la infección por VIH, las formas de prevención de la enfermedad y los principales factores de riesgo. Esto produce un mayor número de ideas erróneas entre esta población, actitudes negativas frente a las personas que padecen la enfermedad, una baja percepción de riesgo o susceptibilidad a la infección y poca autoeficacia para la llevar a cabo actividades de prevención.

Conflicto de intereses: Ninguno a declarar.

\section{Referencias}

1. Organización Mundial de la Salud. Hacia el acceso universal, Expansión de las intervenciones prioritarias contra el VIH/SIDA en el sector de la salud. WHO library. 2008.

2. Programa Conjunto de las Naciones Unidas sobre el VIH/Sida. Informe mundial: ONUSIDA, informe sobre la epidemia mundial de sida 2013. In: ONUSIDA México, DF; 2013.

3. Barceló R, Navarro E. Conocimientos, actitudes y habilidades de los adolescentes escolarizados del sector público de barranquilla (Colombia) relacionados con su sexualidad. Revista Salud Uninorte. 2013;29(2):298-314.

4. García A, Mendoza M, González A, Hernández M, Ginnette P. Conocimientos y prácticas de riesgo ante el VIH/SIDA en adolescentes de la Facultad de Planeación Urbana y Regional de la Universidad Autónoma del Estado de México. Rev Med Inv. 2014; 2(2):121-7.

5. Huitrón G, Denova E, Halley E, Santander S, Bórquez M, Zapata L, et al. Conductas de riesgo en una muestra de adolescentes chilenos y mexicanos: un estudio comparativo. Papeles de población. 2011;17(70):33-47.

6. Buldeo P, Gilbert L. Exploring the Health Belief Model and first-year students' responses to HIV/AIDS and VCT at a South African university. African Journal of AIDS Research. 2015;14(3):209-218.

7. Uribe A. Descripción de los conocimientos, actitudes, susceptibilidad y autoeficacia frente al VIH/SIDA en un grupo de adolescentes colombianos. Pensamiento Psicológico. 2009;5(12):29-43.

8. Sanchiz D, Marchena J, Jarquín E, Costales E. A propósito del SIDA: un estudio cualitativo sobre 
percepción y actitudes de estudiantes y profesorado universitario en Chontales, Nicaragua. Población y Salud en Mesoamérica. 2013;10(2):6-22.

9. Sisay S, Erku W, Medhin G, Woldeyohannes D. Perception of High School Students on risk for acquiring HIV and utilization of Voluntary Counseling and Testing (VCT) service for HIV in Debre-berhan Town, Ethiopia: a quantitative cross-sectional study. BMC research notes. 2014;7(1):518.

10. Díaz Montes CE, Cantillo Uribe L, García Vergara K, Martínez Marenco L, Vega Recuero J. Conocimientos sobre VIH/SIDA en adolescentes de una universidad en Cartagena - Colombia, 2011. Hacia promoc. salud. 2014; 19(2): 38-52.

11. Bernal D. Explotación sexual de niños, niñas y adolescentes: modelo de intervención/Sexual exploitation of children and adolescents: intervention model/A exploração sexual de crianças e adolescentes: modelo de intervenção. Revista Latinoamericana de Ciencias Sociales, Niñez y Juventud. 2013;11(2):617632.

12. Gómez E, Cogollo Z. Conocimiento sobre VIH-SIDA en estudiantes de secundaria de Cartagena, Colombia. Revista de Salud Pública. 2011;13(5):778-784.

13. Bermúdez M, Teva I, Ramiro $M$, Uribe-Rodríguez $A$, Carlos J, Buela G. Knowledge, misconceptions, selfefficacy and attitudes regarding HIV: Cross-cultural assessment and analysis in adolescents1. International
Journal of Clinical and Health Psychology. 2012;12(2):235.

14. Elena R, Escorza F, Gómez G, Gabriela I, Hernández M, Juárez E. Actitud hacia el uso del condón y autoeficacia en la prevención del VIH/SIDA en estudiantes de psicología de la UAEH. Revista Científica Electrónica de Psicología ICSa-UAEH. 2012;(13):28-55.

15. Ballester R, Gil M, Ruiz E, Giménez C. Autoeficacia en la prevención sexual del Sida: la influencia del género. Anales de psicología. 2013;29(1):76-82.

16. Uribe A, Orcasita L, Vergara T. Factores de riesgo para la infección por ViH/Sida en adolescentes y jóvenes colombianos 2010. Act Colomb Psicol. 2010;13(1):1124.

17. Mendoza L, Arias M, Pedroza M, Micolta P, Ramírez A, Cáceres $\mathrm{C}$, et al. Actividad sexual en adolescencia temprana: problema de salud pública en una ciudad colombiana. Revista chilena de obstetricia y ginecología. 2012;77(4):271-279.

18. Uribe A, Vélez T, Barona C. Susceptibilidad y autoeficacia frente al VIH/Sida en adolescentes de CaliColombia. Revista Latinoamericana de Ciencias Sociales, niñez y juventud. 2009;7(2):1513-33.

19. Uribe A, Orcasita L. Análisis de conocimientos, actitudes, susceptibilidad y autoeficiencia frente al VIH/Sida en docentes de instituciones educativas de Cali-Colombia. Revista de Psicología Universidad de Antioquia. 2011;3(1):39-5. 